Ronald A. Cooper FFARCSI,

Rajinder K. Mirakhur MD FFARCS,

Peter Elliott MD FFarCs, Gerald J. McCarthy FFARCS

\title{
Estimation of the potency of ORG 9426 using two different modes of nerve stimulation
}

\begin{abstract}
The potency of ORG 9426, a new nondepolarising muscle relaxant, has been estimated using two different modes of nerve stimulation in patients anaesthetised with thiopentone, nitrous oxide-oxygen and intravenous fentanyl. The force of contraction of adductor pollicis was measured following a single twitch (ST) at $0.1 \mathrm{~Hz}$ or a train-of-four (TOF) mode of stimulation at $2 \mathrm{~Hz}$ every ten seconds. Dose-response curves were constructed using a single-dose method. The $E D_{50}, E D_{90}$ and $E D_{95}$ were 147,272 and $305 \mu \mathrm{g} \cdot \mathrm{kg}^{-1}$ respectively using the ST mode and 125,230 and $257 \mu \mathrm{g} \cdot \mathrm{kg}^{-1}$ using the TOF mode of stimulation. The $E D_{50} \mathrm{~s}$ were not significantly different but the differences between $E D_{90} s$ and $E D_{95} s$ were significant $(P<0.05)$ indicating greater sensitivity of the neuromuscular junction using TOF stimulation. The results of this study suggest that the information obtained by single-twitch stimulation is not the same as that obtained from the first response of the TOF stimulation, suggesting apparently increased sensitivity (and apparently greater potency) with the TOF mode of stimulation. Org 9426 appears to be a drug with relatively low potency.
\end{abstract}

La puissance de l'ORG 9426, un nouveau relaxant musculaire non-dépolarisant, a été estimée utilisant deux différents modes de stimulation nerveuse chez les patients anesthésiés au pentothal, protoxyde d'azote-oxygène et fentanyl intraveineux. La

\section{Key words}

NEUROMUSCULAR BLOCKING AGENTS: ORG 9426; MONTORING: single twitch, train-of-four.

From the Departments of Anaesthetics, Queen's University, Belfast and the Royal Victoria Hospital, Belfast.

Address correspondence to: Dr. R.K. Mirakhur, Department of Anaesthetics, Queen's University of Belfast, Whitla Medical Building, 97 Lisbum Road, Belfast BT9 7BL, Northern Ireland.

Supplies of Org 9426 and financial assistance received from Organon Teknika BV, The Netherlands.

Accepted for publication 16th September, 1991. force de contraction de l'adducteur de pouce fut mesurée après un "twitch " unique (ST) à $0,1 \mathrm{~Hz}$ ou une ondée-de-quatre (train-of-four) (TOF) à $2 \mathrm{~Hz}$ chaque dix secondes. Les courbes de dose-réponse furent construites utilisant la méthode de dose unique. Les $E D_{50}, E D_{90}$ et $E D_{95}$ furent 147, 272 et $305 \mu \mathrm{g} \cdot \mathrm{kg}^{-1}$ respectivement utilisant le mode ST et 125, 230 et $257 \mu \mathrm{g} \cdot \mathrm{kg}^{-1}$ respectivement utilisant le mode TOF. Les $E D_{50}$ ne furent pas significativement différents mais les différences entre les $E D_{90} s$ et les $E D_{95}$ furent significatifs $(P<0,05)$ indiquant une plus grande sensibilité de la jonction neuromusculaire utilisant la stimulation TOF. Les résultats de cette étude suggèrent que l'information obtenue par un * twitch " unique n'est pas la même que celle obtenue par la stimulation TOF, suggérant apparemment une plus grande sensibilité (et apparemment une plus grande puissance) avec la stimulation TOF. Org 9426 apparaît comme étant une drogue ayant relativement une puissance faible.

Previous studies have shown that the mode of nerve stimulation employed has an important effect on the time of onset of action of some muscle relaxants, a train-of-four (TOF) mode being associated with a more rapid block than a single twitch (ST) at $0.1 \mathrm{~Hz} .{ }^{1,2}$ However, it is not known if the mode of stimulation has any influence on the estimated potency of the muscle relaxants.

It has also been perceived by anaesthetists that there is a need for a rapidly acting nondepolarising relaxant preferably with a short to intermediate duration of action and freedom from side-effects. ${ }^{3}$ Currently available nondepolarising relaxants including atracurium and vecuronium have a relatively slow onset of action and suxamethonium is the only available rapidly acting muscle relaxant. However, its use is associated with well documented side-effects. ${ }^{4}$ Org 9426 , a newly developed desacetoxy analogue of vecuronium, has been shown in animal studies to have a faster onset of action with somewhat shorter duration of action than vecuronium. ${ }^{5}$ The present study was designed to estimate the potency of Org 9426 and examine the influence of two different modes of nerve stimulation on its potency. 
TABLE I Patient characteristics

\begin{tabular}{lll}
\hline & $\begin{array}{l}\text { Single twitch } \\
\text { mode }\end{array}$ & $\begin{array}{l}\text { Train-of-four } \\
\text { mode }\end{array}$ \\
\hline$n$ & 36 & 36 \\
Age (yr \pm SD) & $44 \pm 15.5$ & $42 \pm 13.6$ \\
Weight (kg \pm SD) & $71 \pm 14.5$ & $66 \pm 14.4$ \\
Sex (M/F) & $17 / 19$ & $18 / 18$ \\
\hline
\end{tabular}

\section{Methods}

Seventy-two patients aged 18-65 yr of ASA physical status I and II and scheduled to undergo elective ophthalmic or dental surgery were included in the study after obtaining their informed consent and approval from the Regional Medical Ethical Committee. They were premedicated with oral diazepam 10-15 mg 60-90 min preoperatively. Anaesthesia was induced with thiopentone 3-5 $\mathrm{mg} \cdot \mathrm{kg}^{-1}$ and fentanyl 2-3 $\mu \mathrm{g} \cdot \mathrm{kg}^{-1}$ and maintained with $67 \%$ nitrous oxide in oxygen and further increments of fentanyl and/or thiopentone. Ventilation was assisted to maintain end-tidal carbon dioxide concentration between 4.5 and 5\%. A single-dose technique as described previously for relaxants with relatively short duration of action was used. ${ }^{6,7}$

Neuromuscular block was monitored by percutaneous stimulation of the ulnar nerve at the wrist using supramaximal stimuli of $0.2 \mathrm{~ms}$ duration. The resultant force of contraction of the adductor pollicis muscle was recorded using a force displacement transducer and a neuromuscular function analyser (Myograph 2000, Biometer Ltd). Following stabilization of the control responses for about ten minutes, six patients each were randomly allocated to stimulation in a single twitch (ST) mode at $0.1 \mathrm{~Hz}$ or in a train-of-four (TOF) mode at $2 \mathrm{~Hz}$ every ten seconds and to receive $100,150,200,250,300$ or $350 \mu \mathrm{g} \cdot \mathrm{kg}^{-1}$ of Org 9426. The maximum depression of twitch height or of the first response in the TOF $\left(\mathrm{T}_{1}\right)$ was recorded irrespective of the time taken to attain it (time to maximum block).

The twitch height data were subjected to arc-sine transformation as described by Armitage ${ }^{8}$ for responses involving the extreme points ( 0 and $100 \%$ ) on the doseresponse curves. Regression analysis of the data was performed using the method of least squares and doseresponse curves constructed for each mode of stimulation. The slopes of the dose-response curves and the calculated values of $\mathrm{ED}_{50}, \mathrm{ED}_{90}$ and $\mathrm{ED}_{95}$ for each mode of stimulation were tested for statistical difference using a Student $t$ test.

\section{Results}

The Groups were comparable with regard to age, weight and sex distribution (Table I).

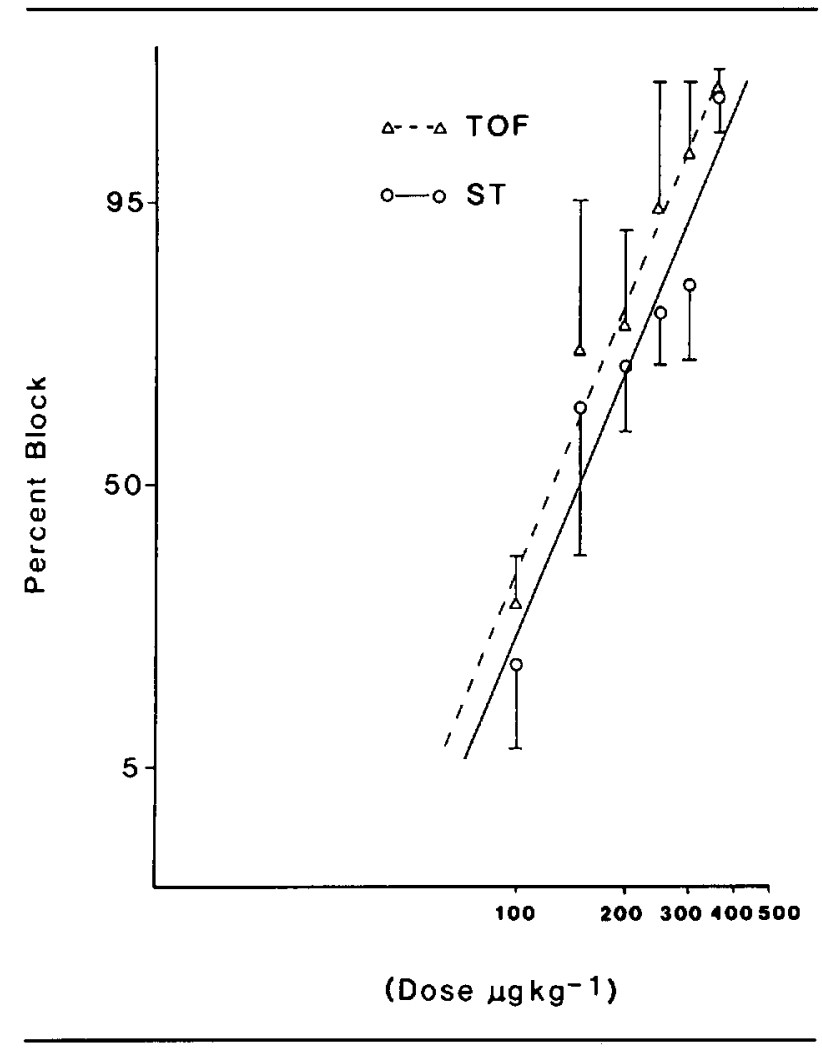

FIGURE Dose-response curves for Org 9426 using single twitch $(\mathrm{O}-\mathrm{O})$ and train-of-four stimulation $(\Delta-\Delta)$. Each point represents the mean block $( \pm S D)$ obtained with each dose.

The average maximum block and the time taken to attain it following each dose are given in Table II and depended upon the dose of the drug given. In general the degree of block attained was greater and the time taken to attain it shorter with the TOF mode of stimulation. The times ranged from 2.8 to $1.7 \mathrm{~min}$ in the TOF groups and from 3.1 to $2.5 \mathrm{~min}$ in the ST groups. The ST depression attained varied from 16 to $99 \%$ and the depression of the $T_{1}$ from 28 to $99 \%$. There were large individual variations in response to Org 9426; one patient who received 100 $\mu \mathrm{g} \cdot \mathrm{kg}^{-1}$ (TOF group) did not exhibit any measurable degree of block while a $100 \%$ block was observed in a patient who received $150 \mu \mathrm{g} \cdot \mathrm{kg}^{-1}$ (ST group).

The dose-response curves for the two groups are shown in the Figure. These did not differ significantly in their slopes but the curve generated from the data using the TOF stimulation was to the left of the one generated using the ST mode of stimulation indicating a greater sensitivity (and an apparently greater potency) using the TOF mode of stimulation. The calculated $\mathrm{ED}_{50} \mathrm{~s}, \mathrm{ED}_{90} \mathrm{~s}$ and $\mathrm{ED}_{95} \mathrm{~s}$ are given in Table III. All the values were lower with the TOF mode of stimulation. The $\mathrm{ED}_{50} \mathrm{~s}$ of 147 and $125 \mu \mathrm{g} \cdot \mathrm{kg}^{-1}$ with the ST and TOF modes of stimulation respectively 
TABLE II Average maximum block after each dose, and time to attain maximum block (ST $=$ single twitch, TOF = train-of-four)

\begin{tabular}{|c|c|c|c|c|}
\hline & \multicolumn{2}{|c|}{$\begin{array}{l}\text { Maximum block \% } \\
(\text { mean } \pm S D)\end{array}$} & \multicolumn{2}{|c|}{$\begin{array}{l}\text { Time to maximum block (min) } \\
\text { (mean } \pm S D)\end{array}$} \\
\hline & $S T$ & TOF & $S T$ & TOF \\
\hline $100 \mu \mathrm{g} \cdot \mathrm{kg}^{-1}$ & $16( \pm 9.0)^{*}$ & $28( \pm 8.9)$ & $2.7( \pm 1.13)$ & $2.2( \pm 0.41)$ \\
\hline $150 \mu \mathrm{g} \cdot \mathrm{kg}^{-1}$ & $65( \pm 28.5)$ & $76( \pm 20.6)$ & $3.1( \pm 0.83)$ & $2.8( \pm 0.95)$ \\
\hline $200 \mu \mathrm{g} \cdot \mathrm{kg}^{-1}$ & $72( \pm 12.5)$ & $79( \pm 12.4)$ & $3.1( \pm 0.84)$ & $2.4( \pm 0.70)$ \\
\hline $250 \mu \mathrm{g} \cdot \mathrm{kg}^{-1}$ & $82( \pm 10.5)^{*}$ & $94( \pm 6.6)$ & $3.0( \pm 0.73)^{*}$ & $1.9( \pm 0.74)$ \\
\hline $300 \mu \mathrm{g} \cdot \mathrm{kg}^{-1}$ & $85( \pm 13.1)$ & $97( \pm 3.9)$ & $2.8( \pm 0.52)^{*}$ & $1.7( \pm 0.52)$ \\
\hline $350 \mu \mathrm{g} \cdot \mathrm{kg}^{-1}$ & $99( \pm 1.6)$ & $99( \pm 1.6)$ & $2.5( \pm 0.97)$ & $1.8( \pm 0.87)$ \\
\hline
\end{tabular}

*Significantly different from the respective TOF group.

TABLE III $\mathrm{ED}_{50}, \mathrm{ED}_{90}$ and $\mathrm{ED}_{95}$ for Org 9426 with the single twitch and train-of-four modes of stimulation. The $95 \%$ confidence intervals are shown in brackets

\begin{tabular}{lll}
\hline & $\begin{array}{l}\text { Single twitch } \\
\text { mode }\end{array}$ & $\begin{array}{l}\text { Train-of-four } \\
\text { mode }\end{array}$ \\
\hline $\mathrm{ED}_{50} \mu \mathrm{g} \cdot \mathrm{kg}^{-1}$ & 147 & 125 \\
& $(130-165)$ & $(109-143)$ \\
$\mathrm{ED}_{90} \mu \mathrm{g} \cdot \mathrm{kg}^{-1 *}$ & 272 & 230 \\
& $(243-304)$ & $(209-252)$ \\
$\mathrm{ED}_{95} \mu \mathrm{g} \cdot \mathrm{kg}^{-1 *}$ & 305 & 257 \\
& $(269-346)$ & $(233-284)$ \\
\hline
\end{tabular}

*Indicates significant difference $(P<0.05)$ between the two modes of stimulation.

were not significantly different $(P=0.07)$. The differences were significant $(P<0.05)$ for the $\mathrm{ED}_{90}$ values of 272 and $230 \mu \mathrm{g} \cdot \mathrm{kg}^{-1}$ respectively and the $\mathrm{ED}_{95}$ values of 305 and $257 \mu \mathrm{g} \cdot \mathrm{kg}^{-1}$ respectively.

\section{Discussion}

The present study shows that the mode of stimulation affects the dose-response and potency of Org 9426, with the TOF mode resulting in an apparently greater potency. Similar results have been obtained for atracurium where Payne and Hughes observed a shift to the left of the doseresponse curve when using tetanic stimulations of short duration, in contrast to single twitch stimuli at $0.1 \mathrm{~Hz}$. ${ }^{9}$ In our study the $\mathrm{ED}_{90}$ and $\mathrm{ED}_{95}$ were different but the $\mathrm{ED}_{50} \mathrm{~S}$ just failed to reach significance $(P=0.07)$. This may be due to relatively large individual variability in the response to muscle relaxants. Although the $\mathrm{ED}_{50}$ is considered a pharmacological measure of comparing potency of drugs, the $\mathrm{ED}_{95}$ is the traditional measure of potency employed in studies of muscle relaxants as it is clinically more relevant.

Both single twitch and train-of-four stimulation are often employed for monitoring the intensity of neuromuscular blockade in clinical practice. ${ }^{10}$ It is believed that the height of the first response $\left(\mathrm{T}_{1}\right)$ in a train-of-four stimulation provides the same information as the single twitch stimulation at $0.1 \mathrm{~Hz}$, provided the trains-of-four are separated by $10-12 \mathrm{sec}$ to allow recovery of the neuromuscular junction between trains. " However, Curran et al. have shown that the method of stimulation affected the onset of action of muscle relaxants, the onset times with the TOF mode of stimulation being shorter.' This was attributed to a stimulation-induced augmentation of the muscle blood flow, which increased delivery of the drug to the neuromuscular junction. It is reasonable to speculate that apparently greater sensitivity is also related to increased muscle blood flow to the stimulated muscles as has been described for the onset of effect. It is also possible that the higher rates of stimulation used in TOF mode induce muscle fatigue and diminish the responsiveness of the stimulated muscle in the presence of neuromuscular blocking agents. Although there is no direct evidence to suggest this possibility with TOF stimulation, stimulus frequency has been shown to reduce the dose of muscle relaxant required and the time for onset of a given degree of neuromuscular block. ${ }^{12}$

It has previously been shown that the frequency of stimulation can influence the dose-response of d-tubocurarine. ${ }^{12}$ Although this relates to frequencies of single twitch stimulation between 0.1 and $1.0 \mathrm{~Hz}$, it is possible that a train-of-four stimulation at $2 \mathrm{~Hz}$ has effects which may persist until the next train at a ten-second interval. Although Lee and Katz ${ }^{11}$ have suggested that there is no difference in the information given by single twitches at $0.1 \mathrm{~Hz}$ and the first response in the TOF applied at ten seconds, there is no published evidence to support this.

From a clinical point of view it is perhaps better to use the dose estimated using single twitch stimulation as a reliable index of satisfactory relaxation for procedures such as tracheal intubation ${ }^{12}$ since it reflects the clinical relaxation of the whole patient, rather than the status of the adductor pollicis muscle which may have been influenced by the TOF mode of stimulation. In any case it is important and relevant to state the method of stimulation used for comparing potencies of different relaxants. 
The $\mathrm{ED}_{90}$ value of $272 \mu \mathrm{g} \cdot \mathrm{kg}^{-1}$ for Org 9426 determined using single twitch stimulation is similar to that (approximately $300 \mu \mathrm{g} \cdot \mathrm{kg}^{-1}$ ) suggested by Wierda $e$ al. in humans ${ }^{13}$ although this was not based on dose-response studies and the mode of stimulation was not specified. Similarly the $\mathrm{ED}_{95}$ of $257 \mu \mathrm{g} \cdot \mathrm{kg}^{-1}$ obtained with the TOF mode of stimulation is similar to that reported by Nagashima et al. ${ }^{14}$

In conclusion, Org 9426 appears to be an agent with a relatively low potency, a class of nondepolarising drugs, proposed by Bowman $e t$ al. to be capable of producing a faster onset of neuromuscular block. ${ }^{15}$ The present study was not designed to assess the speed of onset of action of Org 9426 in doses which would be useful for tracheal intubation. Only smaller doses were employed for determination of the dose-response. However, even with these relatively small doses, the time taken to attain maximum block (Table II) is relatively quicker than is commonly observed after equipotent doses of atracurium and vecuronium. ${ }^{6.7}$ It is likely that Org 9426 may be a nondepolarising relaxant with a fast onset of effect but this will obviously need further studies. The TOF method of nerve stimulation appears to give an apparently higher estimate of potency.

\section{References}

1 Curran MJ, Donati F, Bevan DR. Onset and recovery of atracurium and suxamethonium-induced neuromuscular blockade with simultaneous train-of-four and single twitch stimulation. Br J Anaesth 1987; 59: 989-94.

2 Bell PF, Gibson FM, Mirakhur RK, Clarke RSJ. Comparison of single twitch and train-of-four modes of stimulation for measurement of non-depolarizing neuromuscular block. Br J Anaesth 1988; 60: 343P.

3 Savarese JJ, Kitz RJ. Does clinical anesthesia need new neuromuscular blocking agents? Anesthesiology 1975; 42: 236-9.

4 Durant NN, Katz RL. Suxamethonium. Br J Anaesth 1982; 54: 195-208.

5 Muir AW, Houston J, Green KL, Marshall RJ, Bowman WC, Marshall IG. The effects of a new neuromuscular blocking agent (ORG 9426) in anaesthetized cats and pigs and in isolated nerve-muscle preparations. $\mathrm{Br} \mathrm{J}$ Anaesth 1989; 63: 400-10.

6 Gibson FM, Mirakhur RK, Lavery GG, Clarke RSJ. Potency of atracurium: a comparison of single-dose and cumulative dose techniques. Anesthesiology 1986; 62: 657-9.

7 Gibson FM, Mirakhur RK, Clarke RSJ, Lavery GG. Comparison of cumulative and single bolus dose techniques for determining the potency of vecuronium. $\mathrm{Br} \mathrm{J}$ Anaesth 1985; 57: 1060-2.
8 Armitage $P$. Statistical Methods in Medical Research. Oxford: Blackwell Scientific Publications, 1971; 349-61.

9 Payne JP, Hughes $R$. Evaluation of atracurium in anaesthetized man. Br J Anaesth 1981; 53: 45-54.

10 Ali $\mathrm{HH}$, Savarese JJ. Monitoring of neuromuscular function. Anesthesiology 1976; 45: 216-49.

11 Lee C, Katz RL. Neuromuscular pharmacology. A clinical update and commentary. Br J Anaesth 1980; 52: 173-88.

12 Ali HH, Savarese JJ. Stimulus frequency and doseresponse curve to d-tubocurarine in man. Anesthesiology 1980; 52: 36-9.

13 Wierda JMKH, de Wit APM, Kuizenga K, Agoston S. Clinical observations on the neuromuscular blocking action of ORG 9426, a new steroidal non-depolarising agent. Br J Anaesth 1990; 64: 521-3.

14 Nagashima $H$, Nguyen $H D$, Kinsey A et al. The human dose-response of Org 9426. Anesthesiology 1989; 71: A773.

15 Bowman WC, Rodger IW, Houston J, Marshall RJ, McIndewar I. Structure:action relationships among some desacetoxy analogues of pancuronium and vecuronium in anaesthetized cat. Anesthesiology 1988; 69: 57-62. 